\title{
Galen's De indolentia
}

\section{Essays on a Newly Discovered Letter Ed. by Clare K. Rothschild and Trevor W. Thompson}

[Galens De indolentia. Aufsätze zu einem neu entdeckten Brief.]

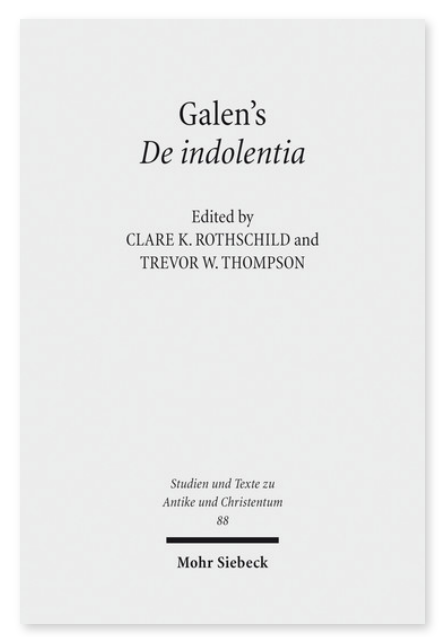

2014. XI, 336 Seiten. STAC 88

ISBN 978-3-16-153216-0 DOI 10.1628/978-3-16-153216-0 eBook PDF 109,00€

ISBN 978-3-16-153215-3

fadengeheftete Broschur 109,00€
Veröffentlicht auf Englisch.

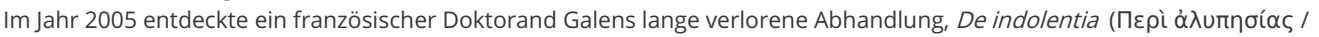

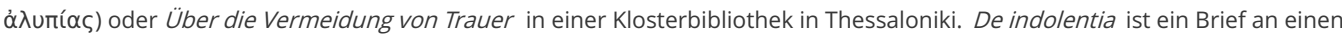
nicht genannten Empfänger, in dem Galen beschreibt, wie er auf das Feuer reagierte, das im Jahr 192 n.Chr. einen Großteil seiner Bibliothek sowie Medikamente zerstörte. Die Handschrift, im Kloster Vlatadon als Codex 14 katalogisiert, ist für Altertumswissenschaftler von unschätzbarem Wert. De indolentia wird Galens Schriften zur Moralphilosophie zugeordnet und liefert wichtige Hinweise auf die literarische Kultur des zweiten Jahrhunderts, darunter auch der Bibliothekskultur in der Antike. Er geht auch auf Themen ein, die von Interesse für Wissenschaftler auf dem Gebiet des antiken Christentums sind. Dieser Band enthält eine völlig neue englische Übersetzung des Textes, eine Zusammenstellung aller Diskrepanzen der führenden kritischen Ausgaben des griechischen Textes und Beiträge von bedeutenden Wissenschaftlern zu den verschiedenen Aspekten des Textes.

Clare K. Rothschild Born 1964; 1986 BA University of California, Berkeley; 1992 MTS Harvard University; 2003 PhD University of Chicago; 2006 postdoctoral fellow Alexander von Humboldt Foundation at Ludwig-Maximilians-Universität München; currently Professor of Scripture, Department of Theology, Lewis University (USA) and Professor Extraordinary, Department Ancient Studies at Stellenbosch University (South Africa).

https://orcid.org/0000-0002-6572-8604

Trevor W. Thompson 1998 BA from Oklahoma Christian University; 2002 MA from Harding School of Theology; 2002 MDiv from Harding School of Theology; 2007 MA from the University of Chicago; currently PhD (Candidate), University of Chicago.

Jetzt bestellen:

https://mohrsiebeck.com/buch/galens-de-indolentia-9783161532160?no_cache=1

order@mohrsiebeck.com

Telefon: $+49(0) 7071-923-17$

Telefax: +49 (0)7071-51104 